IMECE2007-41518

\title{
HAIL EFFECTS ON AIR-CONDITIONER PERFORMANCE
}

\author{
Matthew J. Sitzmann \\ Haag Engineering, Co. \\ 2455 Mclver Lane \\ Carrollton, Texas 75006 \\ U.S.A. \\ msitzmann@haagengineering.com
}

\author{
Frank K. Lu \\ Aerodynamics Research Center, Mechanical and Aerospace Engineering Department, \\ University of Texas at Arlington \\ Arlington, Texas 76019 \\ U.S.A. \\ franklu@uta.edu
}

Steve R. Smith

Haag Engineering, Co.

2455 Mclver Lane

Carrollton, Texas 75006

U.S.A.

ssmith@haagengineering.com

\begin{abstract}
Experiments demonstrated the effects on air-conditioner system performance resulting from dents in fins of their condenser coils and the extent to which conventional fin repair methods restore performance. Two different, commercially available, split-system, residential-type air-conditioners were tested. Flattening substantial areas of the fins caused a reduction in capacity and efficiency of the cooling systems tested. Performance first dropped appreciably when $60 \%$ of the fin areas were pressed flat. Incremental increases in total percentages of areas flattened beyond the first reduction in performance resulted in incremental decreases in capacity and efficiency. Specifically, with $60 \%$ of the fin area flattened on one condenser, system capacity decreased $4 \%$; system SEER (efficiency), $9 \%$. With $100 \%$ of the fin area flattened, system capacity decreased 27\%; system SEER, 34\%. Combing dents from the fins after the extreme case where all fins were flat-
\end{abstract}

tened restored capacity to within $1 \%$ of the undented condition and SEER to within $6 \%$ of the undented efficiency. Similar results were obtained for the second condenser tested.

\section{INTRODUCTION}

The performance of residential and commercial airconditioners has a large influence on electrical energy consumption in the United States. In 2004, households in the U.S. used 216.8 billion $\mathrm{kWh}$ of electricity for air-conditioning, accounting for 6.4 percent of all electricity consumed by residences [1]. Commercial buildings in 2004 consumed an additional 169.9 billion $\mathrm{kWh}$ of electricity for air-conditioning. In 2001, 80.8 million households within the U.S. were airconditioned [2]. In 2003, 3.6 million commercial buildings were air-conditioned [3]. Most of those were in the southwest, south Atlantic, Midwest, and middle Atlantic states [2,3]. 
The number of air-conditioners found in any locale can be attributed to two primary factors: population and climate. The influence of climate is measured by the number of cooling degree days per year. Unrelated to air-conditioning, but very much governed by weather, is the occurrence of hail. Much of the continental United States experiences hail. Areas east of the Rocky Mountains, particularly southwestern and midwestern states are especially prone. It is in those areas that warm moist air from the Gulf of Mexico collides with cold air from the north, creating conditions that favor hail. Figure 1 is a map of the United States depicting locations of all reports of hail $3 / 4$ inch $(19.1 \mathrm{~mm})$ in diameter and larger from 1981 to 1990 [4]. Included on that same map is a breakdown by geographical region of the numbers of residences and commercial buildings with air-conditioning. From the map it is readily apparent that hail-prone regions have many airconditioned buildings.

Hail damage to crops, roofing, automobiles, and aircraft is well documented. The subject of this paper is hail damage to air-conditioning systems. Hail physically affects airconditioning systems by denting their condenser coil fins. Typically, condenser coil assemblies comprise punched and pressed aluminum fins fitted onto copper coils. Fin spacings vary; assemblies commonly have between 8 and 20 fins per inch (3.1 and 7.9 fins per centimeter). The thin cross sections of fins serve well to conduct heat from the refrigerant in the coils and transfer it to air passing by them. But these fins are easily bent. Impacts by even small hailstones fold the fins over. Figure 2 is a photograph of an air-conditioner with hail-dented fins.

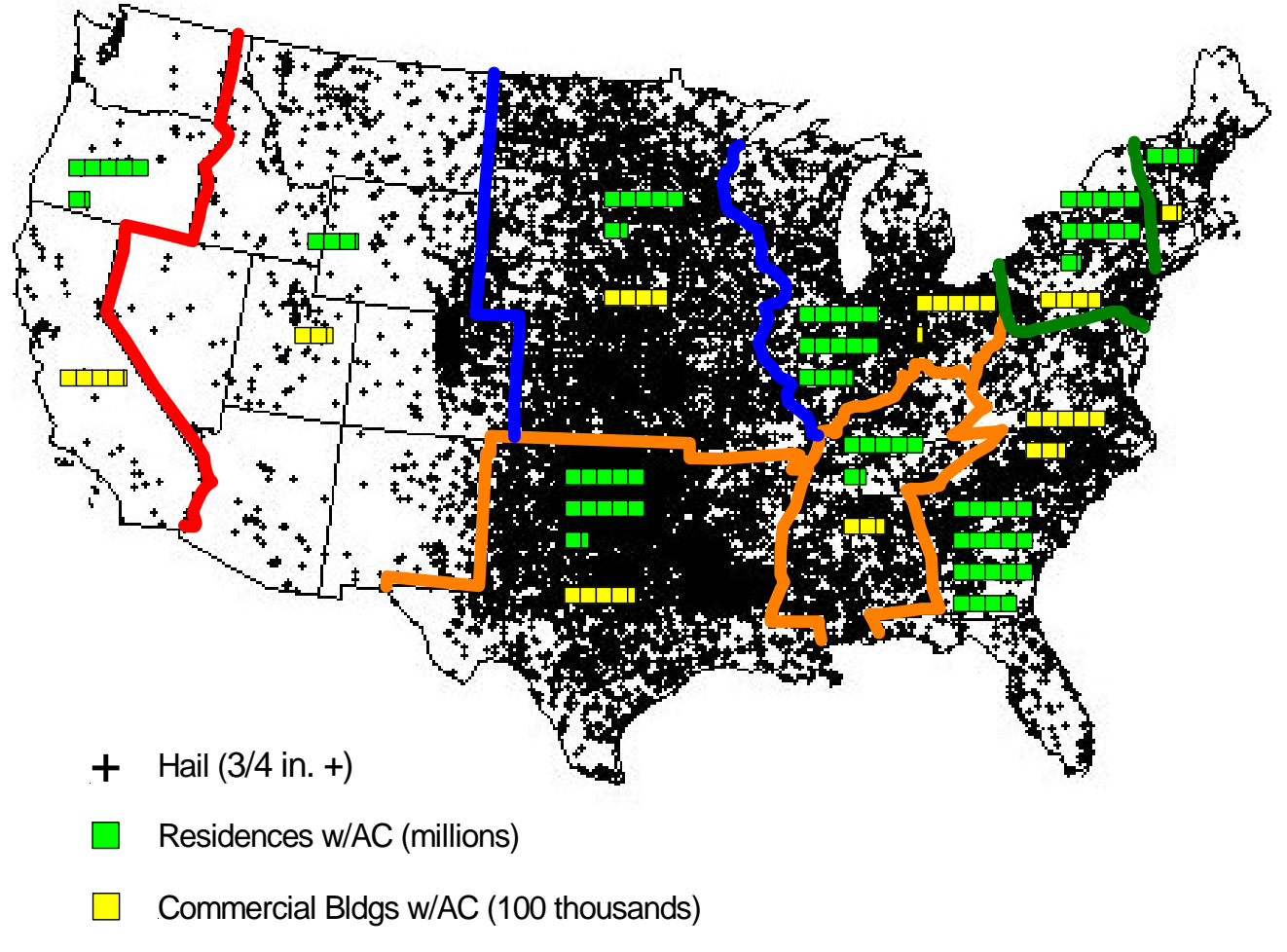

Figure 1. Locations of hailstorms with $3 / 4$ inch $(19.1 \mathrm{~mm})$ and larger hail from 1981 to 1990 [4]. Overlaid on the hail map is the number of residences and commercial buildings with air-conditioning by region $[2,3]$. 


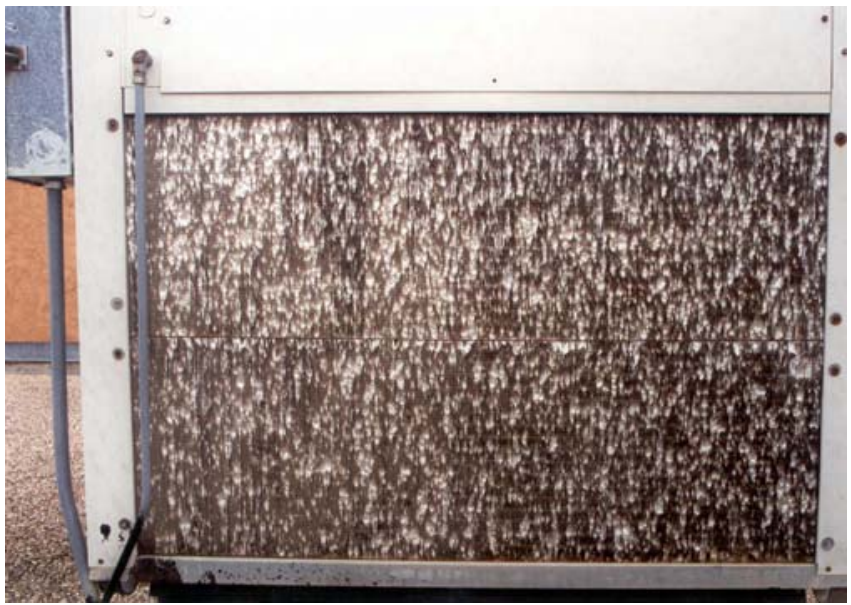

Figure 2. Condenser coil fins of a rooftop air conditioner that were dented by hail.

The goal of this study is to determine the effects dents have on air-conditioner performance and to what extent conventional fin repair methods restore performance.

\section{TEST DESCRIPTION}

Tests were performed to determine the capacity, energy efficiency ratio (EER), and seasonal energy efficiency ratio (SEER) of two separate air-conditioners as increasingly larger portions of their condenser coil fins were dented. All tests were conducted according to ARI 210/240 standards [5,6]. In all cases, the Indoor Enthalpy Method was used for reporting performance. The Outdoor Enthalpy Method was used as a check of the accuracy of the Indoor Enthalpy Method. Duct traverses with pitot tubes mounted in accordance with ANSI/ASHRAE 41.1-2000 [7] measured airflow.

A complete air-conditioning system was constructed using an outdoor condenser, an indoor air handler, and copper tubing to connect the two. The condenser and the air handler were mounted in separate rooms (psychrometric chambers), and auxiliary equipment controlled the environments of both rooms. A duct attached to the air handler discharge captured the airflow leaving it. Pressure, temperature, and relative humidity sensors measured properties of air entering the air handler, leaving the air handler, and entering the condenser. Pitot tubes with differential pressure sensors measured the airflow rate, and a power analyzer measured electricity consumption. Change in enthalpy of the air across the air handler and the airflow rate combined to give the cooling capacity of the systems $[6,8,9,10]$. Dividing the cooling capacities by electricity consumption produced the efficiencies $[5,6]$.

Air-conditioner capacities were measured with the indoor chamber held at $80^{\circ} \mathrm{F}\left(26.7^{\circ} \mathrm{C}\right), 51 \%$ relative humidity, and the outdoor chamber temperature held at $95^{\circ} \mathrm{F}\left(35^{\circ} \mathrm{C}\right)$. Energy efficiency ratio (EER) was measured under those same conditions. Data for calculating the seasonal energy efficiency ratio (SEER) was measured with the indoor temperature at $80^{\circ} \mathrm{F}\left(26.7^{\circ} \mathrm{C}\right)$, the indoor relative humidity at $51 \%$, and the outdoor temperature at $82^{\circ} \mathrm{F}\left(27.8^{\circ} \mathrm{C}\right.$ ) (all environmental conditions listed are nominal). In addition to the parameters required by ARI 210/240, pressure of refrigerant leaving the condenser and temperatures at multiple locations on the

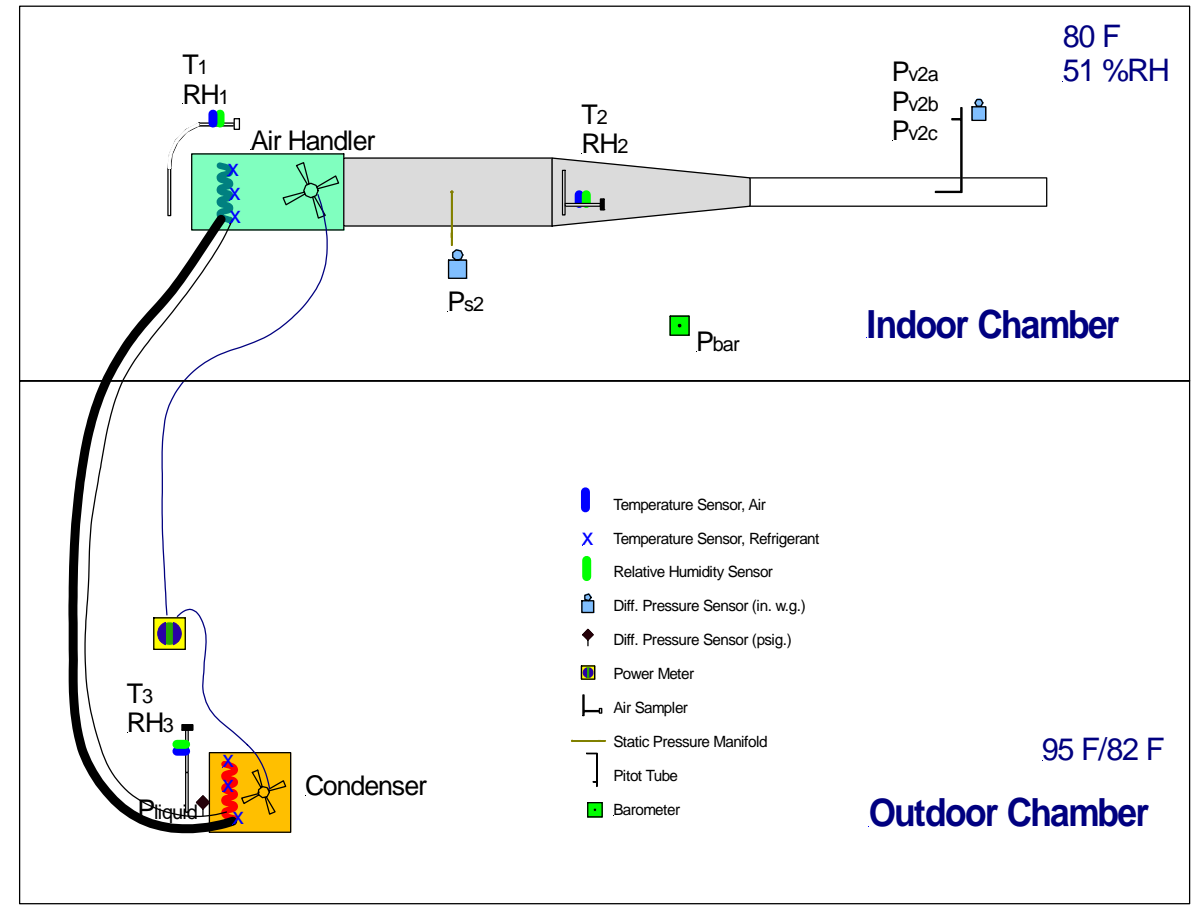

Figure 3. Schematic of test setup for measuring the performance of an air-conditioning system using the Indoor Enthalpy Method. 
evaporator and condenser coils were monitored throughout the tests. Figure 3 is a schematic of the test setup for the Indoor Enthalpy Method. Additional ducts, instrumentation, and a fan were added to the condenser outlet for usage in the Outdoor Enthalpy Method. Figures 4 and 5 are photographs of the laboratory setups.

\section{Air-Conditioning Equipment}

Two commercially available condensers with different manufactures were tested. Each condenser tested had a rated capacity of $30,000 \mathrm{Btu} / \mathrm{h}(8.8 \mathrm{~kW})$ nominal and was coupled with a same-sized air handler. Manufacturer-recommended charges of R-22 refrigerant were used.

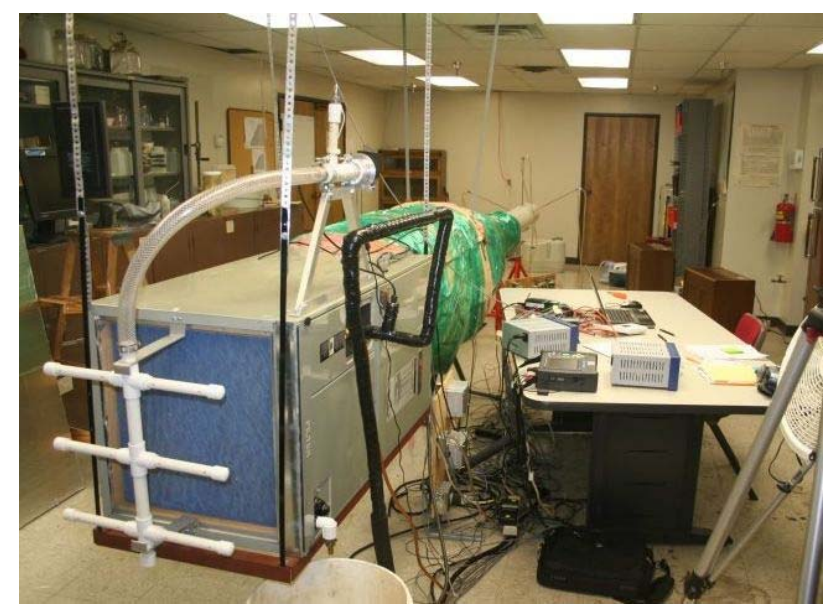

Figure 4. Indoor chamber with air handler, duct, flow measuring device, and instruments.

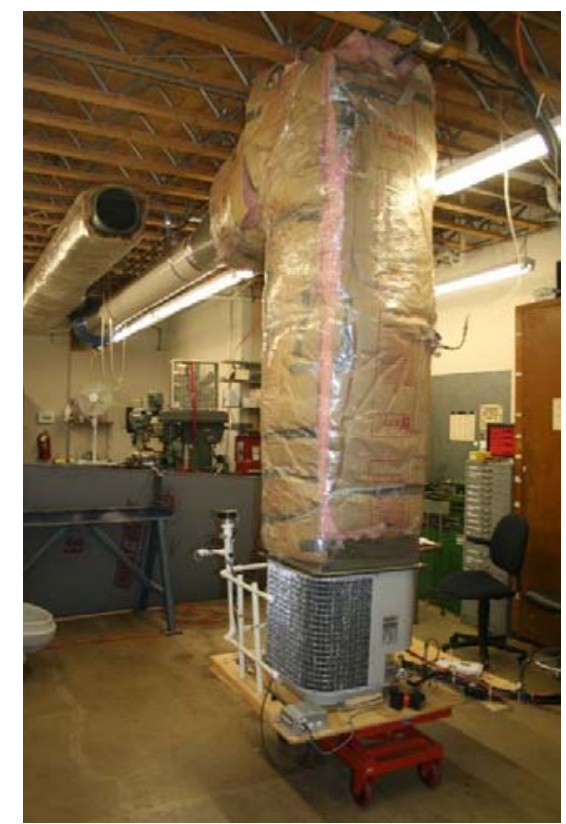

Figure 5. Outdoor chamber with condenser, duct, flow measuring device, fan, and instruments.

\section{Denting Strategy}

A wooden dowel with a hemispherical head on one end, $1 / 2-$ inch $(12.7 \mathrm{~mm})$ radius, was used to dent the fins. Welded wire with a 1-inch $(25.4 \mathrm{~mm})$ mesh stretched over the front of the condensers provided a grid for locating the dents. Each square of the welded wire grid was assigned a letter and a number. A random number generator selected the pattern in which the fins were to be dented.

Dents were formed by manually pressing the denting tool (denter) against the fins. The denter was pressed inward until it flattened fins against the coil. Regions of fins affected by pressing the denter inward were elliptical in shape. The fins were flattened completely in a circular portion of the affected area. Figure 6 is a photograph of a typical dent. The elliptical affected area and circular flattened area are marked for clarity. On unit 1, flattened areas for each dent averaged 0.40 in. $^{2}$ (258 $\mathrm{mm}^{2}$ ). On unit 2, flattened areas for each dent averaged 0.46 in. $^{2}\left(297 \mathrm{~mm}^{2}\right)$. The denter was utilized until ultimately every square in the guiding grid had been dented. To facilitate greater flattened areas, entire sections of the fins were folded over and flattened by hand.

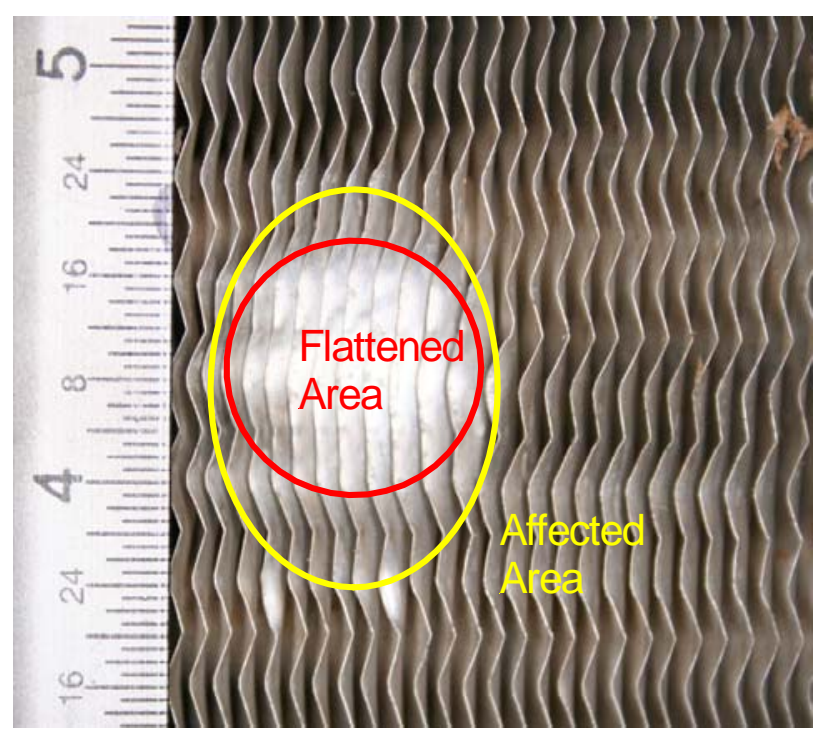

Figure 6. Typical dent in condenser coil fins. The affected area is elliptical in shape (yellow ellipse). The fins are flattened completely within the center of the affected area (red circle), where the denter contacted the fins directly.

\section{Repair Method}

To reverse the effects of denting, conventional fin combs were passed through the condenser coils to straighten the fins. 


\section{Test Protocol}

As built, steel louvers surrounded the condenser coils of both units tested. The units were tested initially with their louvers, then the louvers were removed to expose the coils and the units tested again. Next, dents were made randomly in the aluminum coil fins. Successive tests were performed with increasingly greater numbers of dents until every square of the wire grid had been dented. With every grid square dented, 41\% to $45 \%$ of the fin areas were flattened. The remainder of the fin area was deformed but not flat or unaffected altogether. To increase the flattened fin area beyond the denter's capability, entire columns of fins were folded over mechanically so that no gaps remained between fins in those areas. Columns of flattened fins were added so that $60 \%, 80 \%$, and $100 \%$ flattening resulted. The $100 \%$ flattened condition eliminated nearly all airflow through the condenser. Tests measured capacities and efficiencies of the assemblies for each condition. Finally, the fins were combed and the performances measured again. Figure 7 is a photograph of the denter and the welded wire grid. Figure 8 shows several dented conditions for which tests were run.

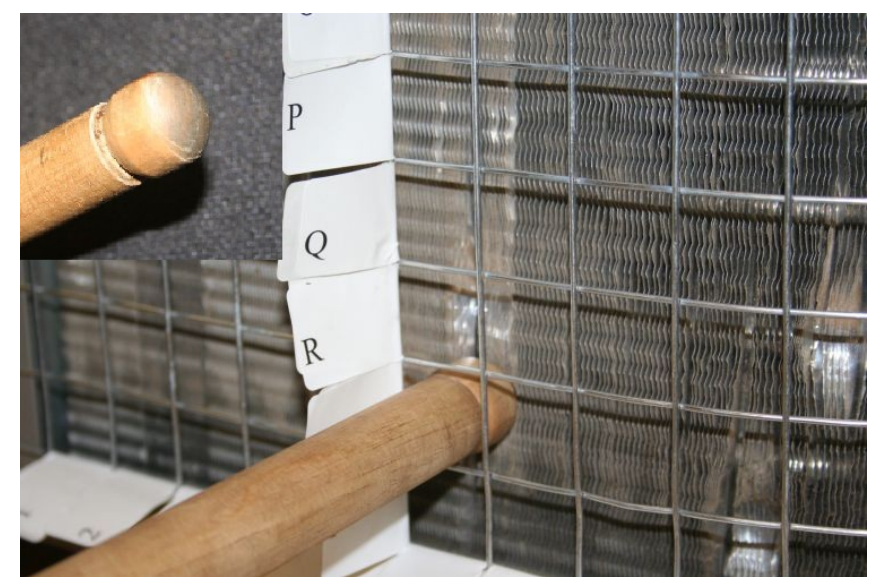

Figure 7. Denter and wire grid. Inset is the rounded head of the denter.
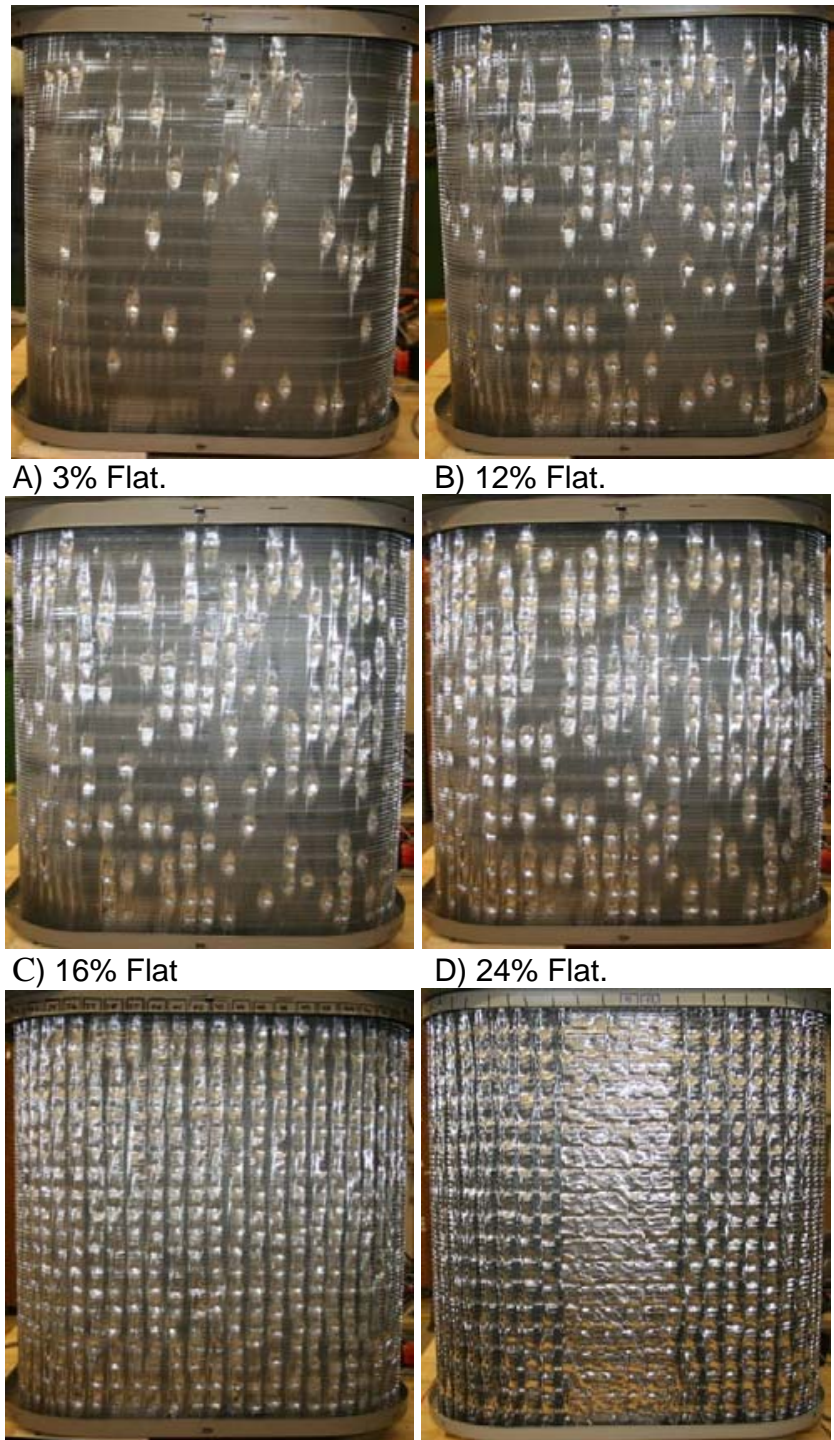

D) $24 \%$ Flat.

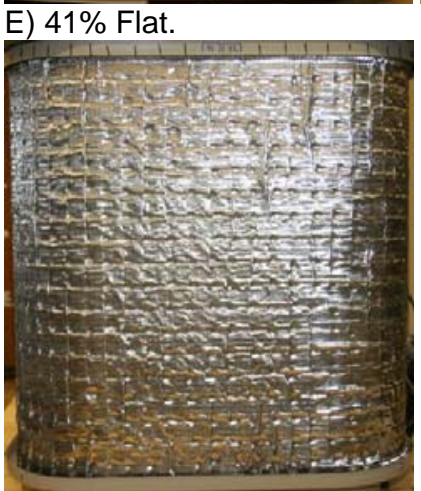

G) $100 \%$ Flat.

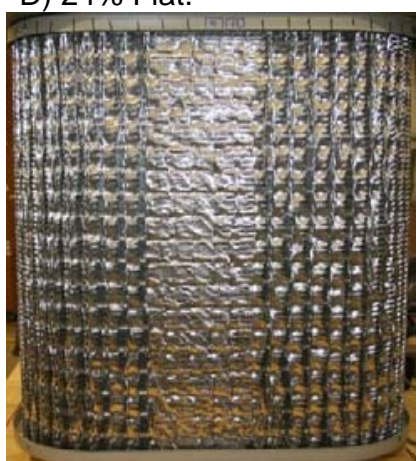

F) $60 \%$ Flat.

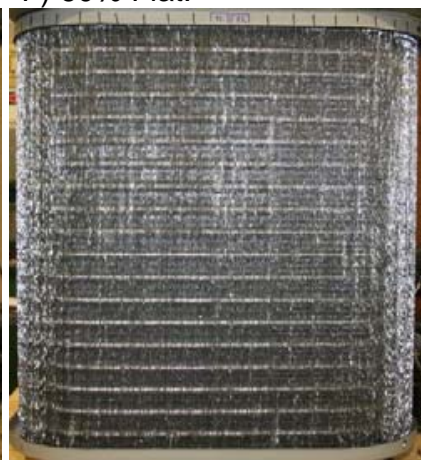

H) Combed.

Figure 8. Dented coil fin conditions. 


\section{FINDINGS AND DISCUSSION}

Denting air-conditioner fins in discrete circular regions throughout the coils had little to no effect on the capacities of the units, even with $41 \%$ of the fin areas completely flattened. Beyond the discrete dents, folding columns of fins so that $60 \%$ of the condenser areas were flattened caused the capacities to drop 4\%. Flattening all of the fins, thereby eliminating nearly all airflow across the condensers, reduced the tested unit capacities $23 \%$ and $27 \%$.

Incremental increases in percentage of area dented caused incremental increases in power consumed by the systems. With all of the fins flattened, power consumption increased from the undented condition $15 \%$ for unit 1 and $19 \%$ for unit 2 . With the entire coil surface covered with discrete dents (the $41 \%$ flat condition), the power consumption of one air-conditioner increased 5\% and the other increased 3\%.
Denting the fins caused reductions in air-conditioner efficiency. The SEER of both units was reduced $34 \%$ in the extreme condition of the coil fins flattened completely. With discrete dents on the entire coil surface (the $41 \%$ flattened condition), the SEER of one unit dropped 5\% and the SEER of the other unit dropped $2 \%$. With the fins completely flattened, EER decreased 35 and $36 \%$. In the $41 \%$ flattened condition, EER decreased 3 and $6 \%$.

Combing dents from the fins after the extreme cases where all fins were flattened completely restored capacities to within 1 and $4 \%$ of the undented capacities and SEER's to within 4 and $6 \%$ of the undented efficiencies.

Figures 9 through 12 depict the capacity, EER, SEER, and power consumption for both condenser units tested. Test conditions included the as-shipped construction (with louvers on), exposed coils with a wide range of dents (with louvers off), and exposed coils after combing.

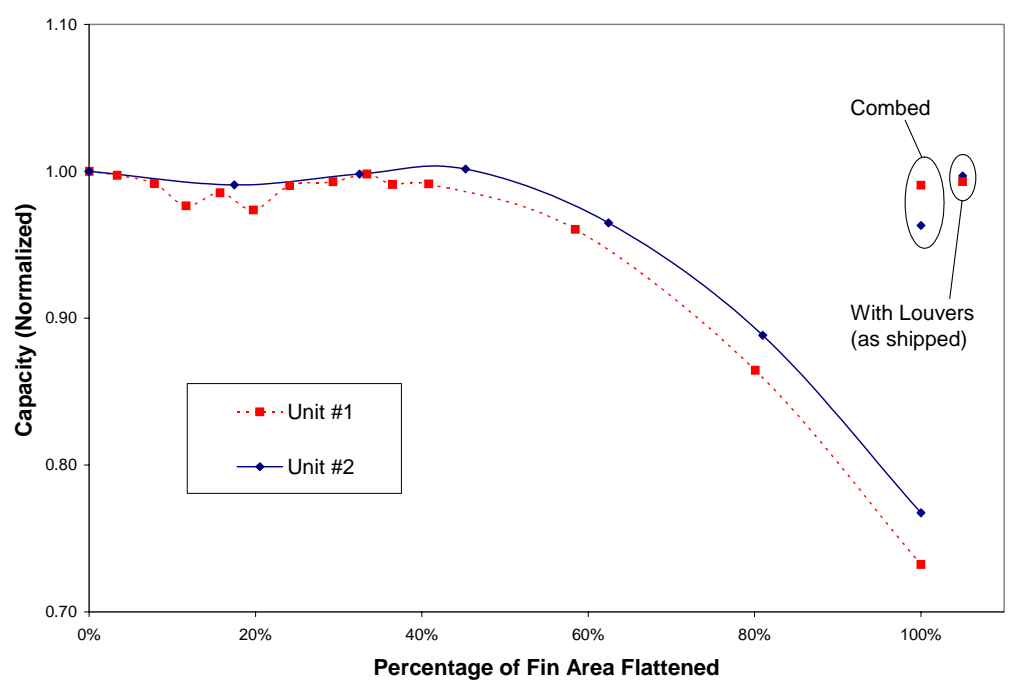

Figure 9. Effects of Fin Dents on System Capacity.

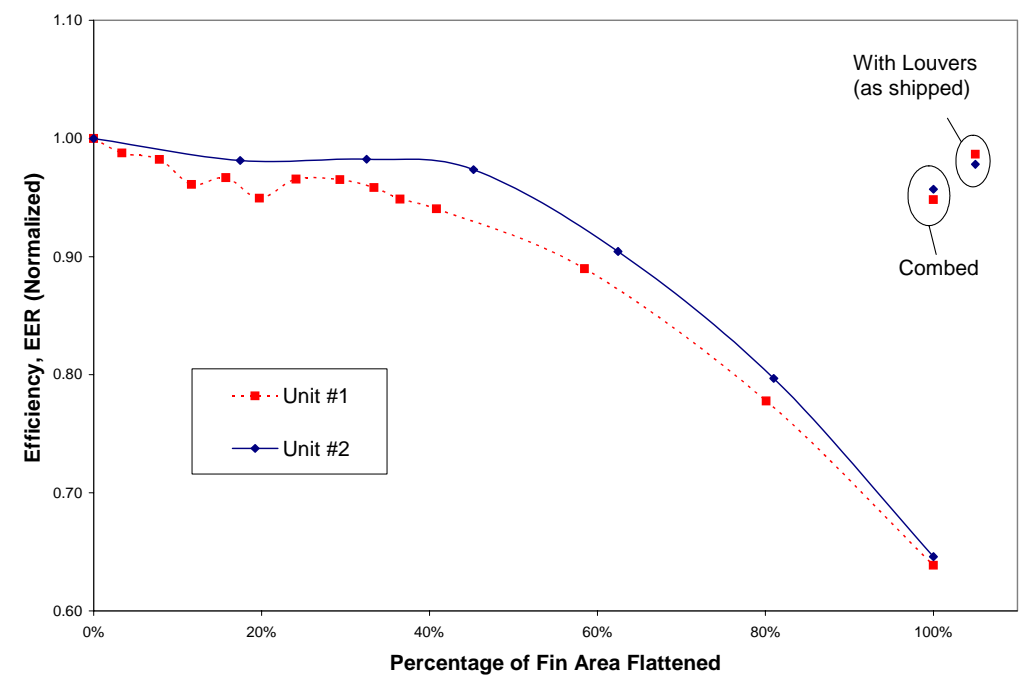

Figure 10. Effects of Fin Dents on Energy Efficiency Ratio (EER). 


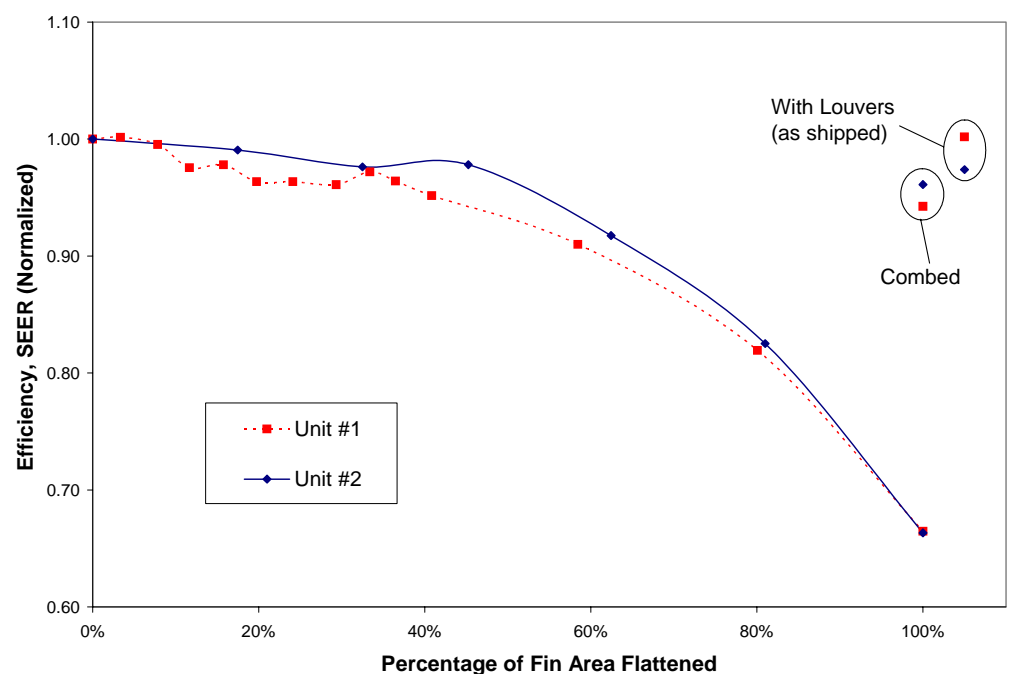

Figure 11. Effects of Fin Dents on Seasonal Energy Efficiency Ratio (SEER).

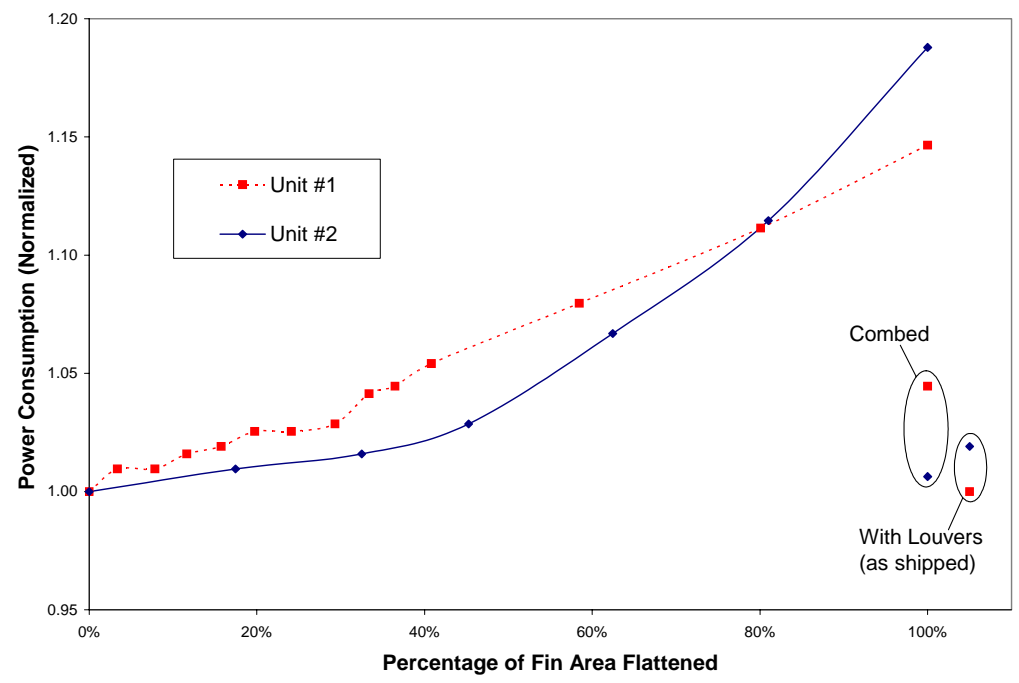

Figure 12. Effects of Fin Dents on Power Consumption. 


\section{CONCLUSIONS}

Experiments were conducted to determine the effects on air-conditioner system performance caused by denting condenser coil fins and the extent to which conventional fin repair methods restore performance. Two separate condensers were tested. With discrete dents spread over the entire surface of the units ( $41 \%$ of the fin area flattened), there were little to no decreases in capacity, 2 and 5\% decreases in SEER, and 3 and 6\% decreases in EER. In the extreme cases where all the fins were flattened completely, one unit lost $23 \%$ of its capacity while the other lost $27 \%$ of its capacity. The EER dropped $35 \%$ for one unit and 36\% for the other. The SEER of each unit decreased 34\%.

Combing dents from the fins after the extreme cases where all fins were flattened completely restored the systems to within 1 and $4 \%$ of their undented capacities and to within 4 and $6 \%$ of their undented efficiencies.

\section{ACKNOWLEDGMENTS}

We would like to thank the University of Texas at Arlington and Haag Engineering for their financial and technical support. Special thanks go to Albert Ortiz for his programming expertise.

\section{REFERENCES}

[1] U.S. Department of Energy. 2006. 2006 Buildings Energy Data Book. Washington D.C.: Office of Energy Efficiency and Renewable Energy.

[2] Energy Information Administration. 2001 Residential Energy Consumption Survey: Housing Characteristics Tables. http://www.eia.doe.gov/emeu/recs.

[3] Energy Information Administration. 2003 Commercial Buildings Energy Consumption Survey: Building Characteristics Tables, Revised June 2006. http://www.eia.doe.gov/emeu/cbecs.
[4] National Climatic Data Center. Hail Events MapESRI ArcExplorer 1.1.

http://cdo.ncdc.noaa.gov/climaps/hail4614.pdf.

[5] U.S. Department of Energy. 10 CFR-Part 430, Appendix M to Subpart B, Uniform Test Method for Measuring the Energy Consumption of Central AirConditioners and Heat Pumps. http://ecfr.gpoaccess.gov/cgi/t/text/textidx?c=ecfr\&tpl=/ecfrbrowse/Title10/10cfr430_main_02.tpl

[6] Air-Conditioning \& Refrigeration Institute. 2006. Performance Rating of Unitary Air-Conditioning and AirSource Heat Pump Equipment, ARI Standard 210/240. Arlington, Virginia: ARI.

[7] American Society of Heating, Refrigerating, and Air-Conditioning Engineers, Inc. 1992. Standard Methods for Laboratory Airflow Measurement, ANSI/ASHRAE Standard 41.2-1987 (RA 92). Atlanta, Georgia: ASHRAE.

[8] American Society of Heating, Refrigerating, and Air-Conditioning Engineers, Inc. 2005. Methods of Testing for Rating Electricity Driven Unitary Air-Conditioning and Heat Pump Equipment, ANSI/ASHRAE Standard 37-2005. Atlanta, Georgia: ASHRAE.

[9] American Society of Heating, Refrigerating, and Air-Conditioning Engineers, Inc. 2006. Standard Methods for Measurement of Moist Air Properties, ANSI/ASHRAE Standard 41.6-1994 (RA 2006). Atlanta, Georgia: ASHRAE.

[10] American Society of Heating, Refrigerating, and Air-Conditioning Engineers, Inc. 2005. 2005 ASHRAE Handbook - Fundamentals, I-P Edition. Atlanta, Georgia: ASHRAE.

[11] American Society of Heating, Refrigerating, and Air-Conditioning Engineers, Inc. 2006. Standard Method for Temperature Measurement, ANSI/ASHRAE Standard 41.1-1986 (RA 2006). Atlanta, Georgia: ASHRAE. 